\title{
STUDY REGARDING THE IDENTIFICATION AND EVALUATION OF RISKS IN THE MANAGEMENT OF A ROMANIAN ORGANIZATION
}

\author{
Raluca Alexandra CEOCEA ${ }^{a}$, Costel CEOCEA ${ }^{b}$, Alina Bianca POP ${ }^{c}$, Aurel Mihail ȚîTUU ${ }^{d}$ \\ ${ }^{a}$ Gheorghe Asachi Technical University of Iaşi, Romania \\ ${ }^{b}$ Vasile Alecsandri University of Bacău, Academy of Romanian Scientists, Bucharest, Romania \\ ${ }^{c}$ Technical University of Cluj-Napoca, Northern University Centre of Baia Mare, Romania \\ ${ }^{d}$ Lucian Blaga University of Sibiu, Academy of Romanian Scientists, Bucharest, Romania
}

\begin{abstract}
Risk management is part of the management process within an organization that can lead to the identification and implementation of potential factors that may threaten the security of the organization, measuring the severity of these factors, reducing effects through prevention and protection, transferring those effects that cannot be managed by the management of the organization. The presented study offers a specific approach to the profile production by identifying and evaluating the risks in the management activity within an organization whose object of activity is the manufacture of certain types of agricultural and forestry machines and equipment. The analysis presented through this study led to beneficial conclusions on the financial diagnosis synthesized by the authors in strengths and weaknesses of the organization, in substantiating opportunities and threats, respectively in assessing possible risks. The study can be used as a model for other organizations and attention can be focused on the risk of decision making from the historical perspective of the scientific theory of decision. It should be emphasized that the paper presented is a point of view of the authors on how to develop and implement the specific process of risk management, how to make decisions and not ultimately to identify the most appropriate techniques, methods and tools that can be applied in the decision-making process within an organization with object of activity focused on the manufacture of forestry agricultural machines and equipment.
\end{abstract}

KEYWORDS: competitive environment, managerial decision, organization, risk.

\section{DOI: 10.24818/IMC/2021/03.08}

\section{INTRODUCTION}

In any field of economic activity there is the problem of risk, because its inevitable presence brings consequences that cannot always be foreseen or anticipated in terms of consequences (Amenc et al., 2016, pp. 64-76).

The last decades highlight an evolution in the appreciation of the notions of risk and uncertainty and the manifestation of three main tendencies in the projection of their stage is observed (Achelis, 2000):

- first of all, it is about the progressive increase of risk and uncertainty situations;

- secondly, there is an increasingly intense use of science resources in risk study processes;

- thirdly, there is an amplification and diversification of the consequences that the applications and techniques of risk analysis have generated in the social environment, in kind or at the level of each economic agent.

\footnotetext{
*Corresponding author. E-mail address: raluca.ceocea@gmail.com
} 

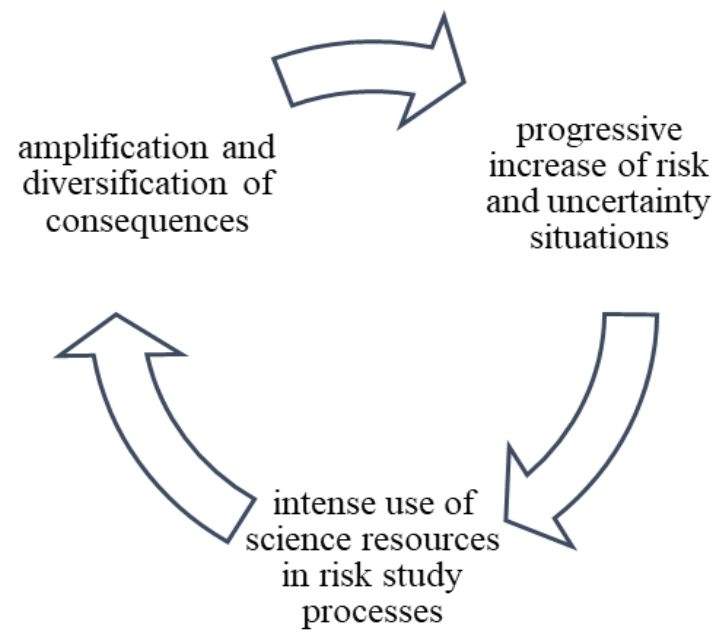

Figure 1. Main trends in the projection of notions of risk and uncertainty

Source: graph processed by the author

These trends are interdependent (figure 1), and the issue of risk is no longer reduced to the saying "who does not risk does not win" (Arjaliès et al., 2017).

In the conditions of increasing the number of risk situations, it is necessary to establish the size of the risk reflected by the size of the effects it generates (Banciu, 2015, pp.67). The multitude of methods that constitute the instrument of determination for the size of the risk effects are based on the use of level indicators that characterize their dimensions at a given moment (Banciu, 2015, pp.16-17). The magnitude of the effects of the risk can be expressed by quantitative or qualitative indicators. In this situation, the risk management and the restriction of the phenomena that disturb the activity of the economic agents involve two complementary dimensions (Ceocea, 2007). One that can be quantified and measured by the level of severity and financial consequences associated with the risk and that allows the financial assessment of possible damages. A second refers to the relationship between costs and risk management (Myakshin \& Petrov, 2019, pp. 55-64). These two components represent the support for diagnosing and applying acceptable or less acceptable solutions in modeling the size of the effects (Cîrnu \& Banciu, 2017). A risk analysis model can be based on three general elements: variability, cost of risk and "treatment" (reaction) of risk (Ceocea, 2010). By variability is meant the size of the damage, the severity and the magnitude of the consequences (Svetlova, 2018). The cost of risk assesses the extent of probable and possible damage (Coqueret \& Guida, 2020). Risk treatment corresponds to the set of techniques that an economic agent applies in order to reduce the consequences and, implicitly, the cost of risk (Davis \& Leo, 2008, pp. 415-426).

The problems specific to the managerial decision manifest themselves in two forms: as a decisional act and as a decisional process (Demiguel et al., 2020, pp.2180-2222). Since there are a multitude of decision-making situations, and the decision-making processes involved are heterogeneous, the analytical approach of the main primary elements of managerial decision is required: the decision maker and the decision-making environment (Grabovy \& Orlov, 2016, pp. 195-202).

The decision-maker is the person or group of persons who, analyzing the proposed objectives, the existing variants and making use of his competences, responsibility and experience, adopts a decision in the respective situation. The decision-making environment is composed of all the internal and external elements of the organization that define the situation subject to the decision and which are directly and indirectly influenced by certain factors, generating significant impulses in the system of decision-making. The decisional environment has a contradictory evolution and a particularly complex character. 


\section{CASE STUDY}

\subsection{Analysis of the organization's internal environment}

The organization in which the management study was conducted was one of the leaders in the production and marketing of seeders for straw and hoe plants, holding a share of $20 \%$ of the domestic market. The best-selling products, in recent years on the domestic and foreign markets are shown in Figure 2.

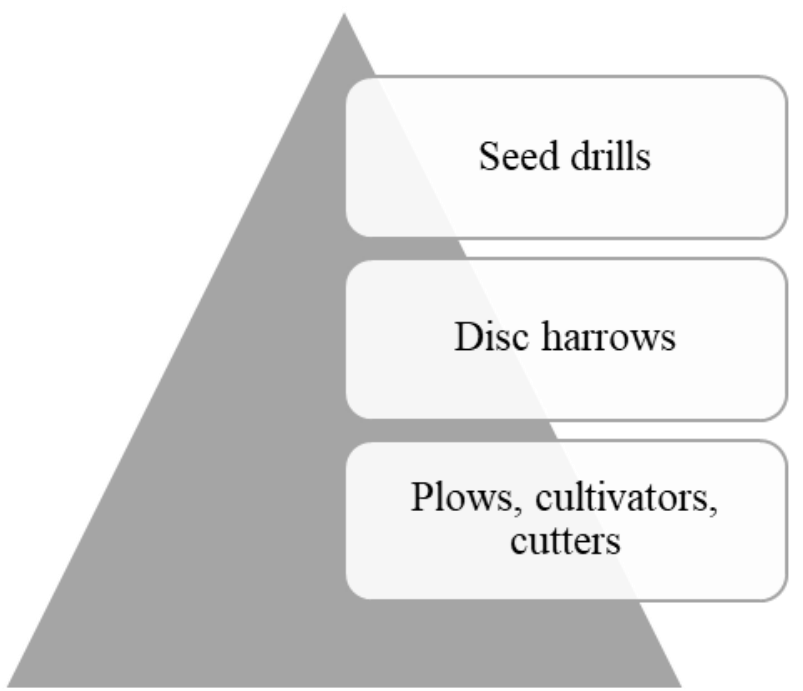

Figure 2. The organization's best-selling products

Source: graph processed by the author

On the domestic market, the organization is a leader in the seed drills sector, holding $70 \%$ of the local production and $60 \%$ of the milling production. It is also a major producer of harrows (35\%), cultivators $(10 \%)$ and plows $(5 \%)$.

The organization addresses mainly the domestic market, its domestic customers representing $80.98 \%$ of the total. The export of products takes place mainly in neighboring countries such as Moldova, Russia, Hungary, Ukraine, Bulgaria, Poland, but also to more distant destinations such as Kazakhstan and African countries, but here occasionally.

The analysis of the internal environment of the organization results in a series of strengths and weaknesses of its activity, and in the external environment a series of opportunities and threats are identified that are interconditioned and whose correlation is essential for a relevant characterization of performance and the organization's development possibilities. It is necessary and useful that the self-relational analysis of the organization's situation be accompanied by a correlative analysis, comparative with the situation of other competitors, thus allowing the shaping of conclusions and action measures that can become potential strategic options in the decision-making process.

The strengths and weaknesses of the organization's activity and the opportunities, respectively the threats identified in the external environment are presented below.

\subsection{Strengths}

- The turnover of the organization registers increases from one year to another, as a result of the increase of sales, in the conditions in which the agricultural field crosses a difficult period;

- Increasing the degree of capitalization of the manufactured production destined for delivery having as effect the reduction of the stocks of finished products and implicitly, the reduction of the costs and the increase of the turnover;

- Increasing the efficiency of the enterprise indicated by the evolution of profitability rates; 
- The organization has new, high-performance equipment, which incorporates state-of-the-art technology, an integrated quality certification system according to ISO and CE standards, giving the organization great flexibility in assimilating new products and the ability to execute certain parts with new technology;

- The organization has numerous investment programs and endowments with electronic computer technology, automation, improvement of working conditions;

- The organization is certified in the quality system by the International Body TÜV CERT through TÜV Management Service Gmbtt;

- The sales network allows the coverage of the entire territory of the country, the customers being easily informed and having immediate access to the desired products;

- The organization holds a large number of patents and registered trademarks that ensure the protection of intellectual property; the research-development activity within the organization ensures the development of new products and the differentiation of the products from its own nomenclature compared to the similar ones of the competitors;

- Good results obtained in terms of domestic market share, due to the distribution channels used;

- Active presence on the markets of European countries, developed from an economic point of view (Poland, France, Germany, Italy);

- The organization's trade receivables have increased by improving sales activity, by applying an attractive customer lending policy by extending customer collection terms;

- Trade debts are decreasing, not due to the decrease in the volume of supplies of materials, but due to obtaining longer payment terms;

- Annually, the organization conducts over 20 training and refresher courses for employees that included a number of over 350 employees;

- The organization has experience and tradition in the field.

The organization is one of the leaders in the production and marketing of seeders for straw and hoe plants, holding a $20 \%$ share of the domestic market.

The organization enjoys a good image due to the long period of activity, the large number of cars delivered, both domestically and for export, which are in operation and have good reliability. The reputation enjoyed by the organization, the long presence and the dynamics on the market were possible, first of all, due to the creative capacity of the staff and the efficient management.

\subsection{Weaknesses}

- The profit rate fluctuates from one year to another;

- Average annual labor productivity decreases;

- The economic correlation is not observed: ICA > IFS > INS (ICA $=103.3 \%$, IFS $=96.71 \%$, INS $=97.89 \%$ ) (the salary fund decreases more than the number of employees decreases);

- In previous years, the economic and financial results were not achieved at the levels provided in the Revenue and Expenditure Budget;

- The organization laid off employees from one year to the next, based on a restructuring plan;

- The level of training of employees is average (following the evaluation of the staff, approximately $40 \%$ received grades between 6 and 7 and the rest between 8 and 10);

- Low degree of capacity utilization of the organization (approximately $71.4 \%$ for buildings and $29 \%$ for machinery);

- The existence in organization of outdated, energy-consuming and low-productivity equipment that determines additional costs for mechanical processing and corrosion protection;

- The large dimensions of the organization, create problems of administrative nature, the industrial park not realizing its purpose for which it was established; 
- Lack of a high-performance integrated IT system that allows the management team to make decisions based on real-time data;

- In terms of domestic sales, the organization had to maintain the sale with payment in installments in order to cover the very long periods between the offer made by the organization and the completion of projects submitted by customers in order to obtain the necessary funds;

- During the analyzed period, the number of customer collection days was doubled;

- The results registered for export were below the level of provisions.

The problems that Romanian agriculture has faced in recent years have also influenced the evolution of related industries, as is the case of the agricultural equipment and machinery industry. An important attention was paid to the study of the context of the evolution of the Romanian economy and of the strategic orientations in the field of production and commercialization of agricultural machines and equipments.

Although the forecasts for the next five years, made by national policy documents, and especially those of accession to the European Union, mentioned a favorable evolution of the Romanian economy with very high GDP growth rates, the current situation proves the fragile stability of the Romanian economy. unfavorable conditions of both internal and external origin.

\subsection{Opportunities}

- Prospects for the development and modernization of agriculture, increasing the attractiveness and possibilities of starting a business in rural areas;

- Adoption and compliance with European standards;

- The possibility of capitalizing on the opportunities generated by the internal market through post-accession programs;

- Development of procurement procedures for agricultural machinery by accessing structural funds;

- Development prospects on foreign markets;

- Possibilities for collaboration and strategic alliances with partners that have complementary production;

- Increasing the share of foreign direct investment;

- The poor endowment of agriculture with agricultural machines and equipment compared to the level of the other European states as well as the antiquity of some equipment's that now serve agriculture offer good conditions for the development of the production specific to the organization;

- Development of the market of alternative energy resources and alternative fuels that will have to be provided by agriculture;

- Trends in the rapid evolution of agricultural technology;

- Access to modern technological solutions;

- Possibilities to capitalize on new customer niches (in the energy or aeronautics field);

- Romania has a cheap and skilled labor force;

- Prospects for increasing the agricultural market and the average gross wage in agriculture;

- Romanian organization has a tradition in terms of agriculture;

- Romania's relief favors the development of the agricultural field.

A positive factor is the entry of structural funds into Romania, with favorable effects on economic developments, including exchange rates, development and modernization of agriculture, despite the fact that the absorption rate will probably be low, judging by the experience of countries in the region. European Union.

The specialists estimate that the share of foreign investments will remain high, which will diminish the external imbalances of the Romanian economy, according to some forecasts of the evolution of 
the economy. Romania's economic prospects are strongly influenced by its external climate, given the importance of European Union markets for Romanian exports, its large external financial needs, and the contribution in the form of managerial knowledge that foreign investors can bring in new and existing companies.

\subsection{Threats}

- The intensification of the competition exerted by similar companies from the country or from abroad constituting a preoccupation of the organization that is put in the situation to face the pressure exerted either by the new or second-hand products that will enter very strongly on the Romanian market;

- Industrial specialization; more and more companies turn to specialized manufacturers who produce components at low costs, managing to reduce the costs of their products;

- The poor quality and the very high prices of the raw materials and subassemblies available on the Romanian market and the reduced sort-type-dimensional supply of metallic materials determine the organization to sometimes turn to producers and they cannot deliver the necessary quantities which are too small compared to their delivery standards;

- Decreased purchasing power of farmers in Eastern Europe, who face situations similar to those in Romania;

- The downward trend in sales of agricultural machinery and equipment on the domestic market as a result of reduced subsidies for the purchase of agricultural machinery and equipment;

- The market for agricultural products is still in difficulty, with their prices remaining low;

- In the foreign market, the sale of agricultural machinery and equipment is difficult due to the measures adopted by the governments of the countries with which the organization has traditional trade relations;

- Lack of own programs of the Romanian Government to support agricultural producers;

- Failure to finalize the organizational and institutional framework meant to ensure the absorption of European funds;

- The difficult development of PNDR due to the fact that, in order to obtain the financing, the client needs the entire amount, following that after the acquisition and payment he will receive $50 \%$ of it; thus appears the difficulty of paying the contracted debts on time;

- Very high fixed costs to be borne by organizations in the field;

- Agriculture still broken;

- Non-cultivation of important arable land (over 30\% of the total);

- Calamity of some agricultural areas (approximately $40 \%$ of the arable area) and of some crops with a large share (corn, sunflower).

Among the threats that will influence Romania's economic prospects in the coming years are: access to structural funds; increasing export potential; connection to European Union networks; shocks that may occur in terms of exchange; access to international capital markets.

Unprecedented increases were recorded in almost all areas of activity, while agriculture seems to have gone through the weakest year since the post-December period. The disastrous results in agriculture, doubled by the deepening of the labor crisis, are phenomena that have already begun to make their mark on the evolution of inflation, through the increasing acceleration of prices.

The threat of declining agricultural profitability could lead to the decision of producers of goods and equipment in this field to reorient to other more profitable sectors.

In the conditions of a technical progress and an accelerated technological development, the requirements of adaptability and innovation increase for the respective organizations, increasing at the same time the demand for the equipments with special performances within the agricultural processes. However, a satisfactory profit margin cannot be obtained without investment. After several years of weak agriculture that seriously influenced the activity in the sector, the effects were 
also felt in the industrial sector, many of the enterprises of design and production of agricultural machinery and equipment being threatened with bankruptcy. Efforts to facilitate trade that have generated the trend towards liberalization have been undertaken both regionally and globally, and have resulted in regular and progressive reductions in barriers to international trade.

In an agriculture undergoing technical and social restructuring as Romanian agriculture is currently presented, the increase of the endowment with technical equipment depends on the capacity of the existing producer organizations on the market to cover the demand for them, both in terms of quantity and and from a qualitative point of view.

Establishing the internal and external context was the first step in identifying the risks facing the organization.

\section{POSITIONING OF THE ORGANIZATION IN THE COMPETITIVE ENVIRONMENT SPECIFIC TO THE FIELD OF ACTIVITY}

The quality of the managerial process is subject to a set of restrictions generated by conditioning of the decision-making context (quality of information available in terms of accuracy, completeness and timeliness, time pressure, risk) and is influenced by managers' managerial skills (ability to process information, personality and the way of perceiving reality).

In order to strategically diagnose the field of activity in which the organization operates, the model of the five forces of Michael Porter is applied.

The model is based on the analysis of five factors that exert their influence in the competitive environment specific to the field of activity. These factors will be further addressed.

\subsection{Analysis of the rivalry between the existing companies within the activity sector}

Regarding the market share held by the analyzed organization, significant percentages can be approximated to the group of tillage machines and to the group of seeders.

The organization is one of the strongest national organizations for the production and marketing of straw and hoe planters, a fact embodied by the ownership of over $20 \%$ of the domestic market. By product groups, the market share is: $15 \%$ for plows; $45 \%$ the grape; $50 \%$ cultivators; $75 \%$ seeders. Some of the agricultural machinery companies have seriously felt the effects of the market economy, reaching the point of reducing their activity or even ceasing it. However, competition can still be seen as quite intense on the following grounds:

- There are also other companies with an active presence in the field, which have significantly equal competitive forces. Particular attention is paid to companies that sell new and used agricultural machinery;

- We can still talk about a fragmented agriculture and a sector of activity that in recent years has registered a low pace of development;

- Fixed costs occupy a significant share in the cost structure specific to the field - large production and logistics capacities, which require special investments that can be recovered only through large production volumes and high market shares;

- The differentiation from the products offered by the competition is quite weak;

- The existence of high barriers to exit the sector that resides in the difficulty of orienting oneself to another field of activity.

The good results obtained by the organization in terms of domestic market share are due to the distribution channels used by the organization. Simultaneously with the sales activity, the distributors also fulfill the attributions of market information providers regarding the customers' requests, the technical problems they face both during the warranty and post-warranty period, at the same time as receiving the proposals made by the customers regarding the improvement. technicalfunctional parameters of the products. The marketed products are registered as an industrial mark, 
having certification of work safety and quality level according to ISO 9001 norms, offering guarantees to the beneficiaries regarding the level of quality and reliability in operation, this being an essential competitive advantage.

\subsection{Analysis of the entry of new competitors in the field of activity in relation to the degree of threat they present}

The accentuation of the competition occurred as a result of the entry on the Romanian market of numerous companies that sell foreign, new and used agricultural machines and equipment at more advantageous prices than those of the domestic producing companies. The new competitors have additional production capacity and resources and will fight for increased market share and profit sharing. This aspect, corroborated with the difficulty of the organization's internal customers in obtaining the necessary funds for the purchase of agricultural equipment determined the organization to maintain the sales with payment in installments.

\subsection{Analysis of the degree of threat of substitution products}

Regarding the field of production and sale of agricultural machinery and installations, it is not possible to talk about the existence of substitutes to which the existing demand can migrate. The physical work of agricultural workers or the methods of tillage with machines put into operation with the help of animals could be discussed here. However, given the need to comply with European standards and norms and with a view to relaunching, modernizing and developing the agricultural sector at national level in the coming years, these traditional means are completely replaced by mechanized and automated technical solutions or are at most complementary to the latter.

\subsection{Analysis of customers' negotiation power}

The organization's clients are numerous, with relatively high bargaining power, considering that the organization's products are increasingly competing with similar or more efficient products and with lower prices, brought from abroad on the Romanian market.

In order to increase revenues, in terms of domestic sales, the organization had to maintain the sale with payment in installments to cover long periods between the offer made and obtaining the necessary funds by the organization's customers and at the same time the collection period of receivables almost doubled. Particular attention must be paid to maintaining and increasing the number of customers in the foreign market by offering high quality products and in advantageous conditions.

\subsection{Analysis of the negotiation capacity of the suppliers}

The organization's supply of raw materials and materials was made from commercial companies following the auction at the Romanian Commodity Exchange Piatra Neamţ Terminal. Following a series of negotiations, the organization obtained discounts from the total value of the goods and payment deadlines. For the materials entered for the consumption of agricultural machines, the supply is made on the basis of orders. A special place was represented by the supply of landmarks from collaboration-cooperation. The start-up presented difficulties as it was necessary to transfer the SDVs, to approve them from a technical point of view and to negotiate the delivery prices. For materials for which there are no domestic products, it was necessary to extend the cooperation in the field of imported materials and parts.

At this stage, the organization is not dependent on a single customer or a single supplier whose loss would have a negative impact on the organization's revenues. 


\section{CONCLUSIONS}

Considering all the aspects presented in the paper, the organization can opt for a development strategy, thus ensuring the necessary context for market differentiation and consolidation of the competitive position. In this sense, it will focus on obtaining a superior performance that will ensure a good position in the sector in terms of one of the following attributes: quality of products offered, after-sales services and facilities offered to customers, technology used, originality of products, product distribution channels, compliance with delivery deadlines, ability to adapt to changes in the environment and customer requirements. For this, the organization needs intuition and creativity, increased capabilities in terms of capitalizing on its strengths, compared to its competitors. The organization also needs enhanced marketing capabilities to enable it to identify and understand individual customer requirements and differentiators from competitors, as well as establish opportunities to meet them.

The analyzed organization enjoys a good image due to the long period of activity, the large number of cars delivered, both domestically and for export, which are in operation and have a good reliability. The reputation enjoyed by the organization, the long presence and the dynamics on the market, were possible, first of all, due to the creative capacity of the staff and the efficient management.

If it manages to exploit the opportunities offered by the economic environment and overcome the obstacles, the organization will be in the future, an active presence on the market of agricultural machinery and equipment taking advantage of its long experience and investment opportunity in agriculture.

The limitations of this study relate to uncertainty factors, such as the lack of financial support for agricultural activities, through government policies that affect or could affect the organization's liquidity, cash flows, and in this context measures must be taken to reduce inventories and increase receivables to generate excess liquidity for the organization that will have to cover the necessary investment activities and reduce the level of loans. Adopting vigorous measures to reduce the recovery period of debts and finding financiers for commercial activity in order to reduce the degree of indebtedness will eliminate the financial deficit of the organization, balancing the balance of receipts and payments.

It is also necessary to analyze the situation of stocks without movement in order to detect the causes of their creation and to find solutions for capitalization, including through successive price reductions.

The organization's specialization, especially in the field of tillage machines and seeders, the purchase of machine tools that incorporate state-of-the-art technology offers possibilities for collaborations and strategic alliances with partners that have complementary production. The strength of the organization can allow the conclusion of mergers that will lead to gaining new market shares.

The organization must consider increasing the use of production capacity by developing new businesses such as making "sandwich" panels, with a high technical equipment that also allows the production of high-quality parts and subassemblies for companies in the sector. energy or aeronautics.

The analysis shows that organization has development opportunities generated both by the need for agricultural development to provide food for the population and by the development of the market for alternative energy resources and alternative fuels (refineries with a required share of biodiesel).

In the future, the internal market will benefit from a very good opportunity to purchase agricultural machinery and equipment. Over 991 million Euros are available for the modernization of agricultural holdings, non-reimbursable funds that can be accessed. 
In order to maintain market shares and achieve turnover, the organization can take the measure of increasing the share of contracts for sale with payment in installments and leasing, subleasing, but this involves ensuring adequate financing and the results are not immediate.

Actions are needed to ensure the information and presentation of the organization, the products sold by it through specific means of advertising both in Romanian and in the main languages of international circulation, ensuring the promotion of products through demonstrations in major agricultural basins of the country, proximity to professional associations agricultural profile, proximity to agricultural research institutions, participation in fairs and exhibitions of agricultural machinery and equipment in the country and abroad.

In order to limit the negative effects caused by the non-performance of the production activity and the efficiency indicators, a series of measures can be adopted:

- Cooperative release of a significant volume of parts and subassemblies;

- Analysis and identification of products from the portfolio, with low profitability and the transition to their realization in specialized sectors (small series product sectors);

- Redesigning subassemblies of cars from the same family to allow their launch on subassemblies (typing subassemblies with the same functional role; example: bodies, coulters);

- Realization of metal products based on economic contracts;

- Carrying out the import activities of some agricultural machines and equipment's that are not part of the organization's production, thus coming to meet the internal customers.

In order to align with the norms imposed by the European Union, it is necessary to carry out modernization, development, investment programs and a development strategy of the organization in order to capitalize on the identified opportunities. These cover a number of directions, as follows:

- Obtaining the authorization to operate the organization according to the European environmental and labor protection norms;

- Increasing the competitiveness of products by increasing the quality level;

- Decreasing production costs, increasing labor productivity and decreasing energy consumption;

- Improving working conditions and increasing employees' incomes. The employed staff follow various forms of training in order to be up to date with the European legislation, as well as with the efficient technical level of the commercial companies from the EU countries. It is essential that some of the employees move to these countries; visits to fairs and exhibitions of agricultural machinery, industrial machinery and installations, visits to companies building such installations in countries such as Germany, Poland, Italy;

- Reducing the impact of the activity on the environment (reduction of heavy metal pollution, keeping them within normal limits, control of iron and other ferrous and non-ferrous metals, pollution with salts and sulphates, oil residue content in the area of oil separators for heat treatments or at the fuel depot).

- Periodic performance of risk analysis and implementation of a risk management system within the organization.

\section{REFERENCES}

Achelis, S., B. (2000). Technical Analysis, Ed. Probus Chicago IL.

Amenc, N., Ducoulombier, F., Goltz, F., Lodh, A. \& Sivasubramanian, A. (2016). Diversified or concentrated factor tilts? Journal of Portfolio Management, 42 (2), 64-76.

Arjaliès, D., L., Grant, P., Hardie, I., MacKenzie, D. \& Svetlova, E. (2017). Chains of Finance: How Investment Management is Shaped, Oxford, U.K: Oxford University Press.

Banciu, D. (2015). Colaborarea şi cooperarea - soluţia succesului instituţional. Biblioteca - Revistă de Bibliologie şi Ştiinţa Informării, 3, 67, ISSN 1841 - 1940. 
Banciu, D. (2014). Agenda Digitală I2020, din perspectiva oportunitățilelor de business. Finanțe și Afaceri, 93, 16-17

Ceocea, C. (2010). Riscul în activitatea de management, Editura Economică, București

Ceocea, C. (2007). The 5th International Conference on the Management of Technological Changes, Chania, Greece, „The Capital Market's Risks - an aggregated risk”, 2, pp. 413, Editors: Costache RUSU, Nicolae BADEA, August 25-26, 2007, Democritus University of Thrace, Greece, 2007.

Cîrnu, C., E. \& Banciu, D. (2017). Open Data: Support for Open Government - Case Study Romania. Administration and Information Systems Journal, issued by The Institute of Administrative Information System, Tokyo, Japan.

Coqueret, G. \& Guida, T. (2020). Machine Learning for Factor Investing: R Version. Financial Mathematics Series.

Davis, M. \& Leo, S. (2008). Risk-sensitive benchmarked asset management, Quantitative Finance, 8 (4), 415-426.

Demiguel, V., Martín-Utrera, A., Nogales, F. \& Uppal, R. (2020). A Transaction-Cost Perspective on the Multitude of Firm Characteristics, The Review of Financial Studies, 33 (5), 2180-2222.

Grabovy, P., G. \& Orlov, A., K. (2016). The Overall Risk Assessment and Management: Implementation of Foreign Investment Construction Megaprojects by Russian Development Companies, Procedia Engineering, 153, 195-202.

Myakshin, V. \& Petrov, V. (2019). Evaluating the investment attractiveness of a region based on the balanced scorecard approach, Regional Science Inquiry, 11, 55-64.

Svetlova, E. (2018). Financial Models and Society: Villains or Scapegoats? Cheltenham, U.K: Edward Elgar Publishing. 